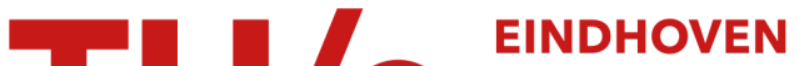 UNIVERSITY OF TECHNOLOGY
}

\section{Sub-micron polymeric stomatocytes as promising templates for confined crystallization and diffraction experiments}

Citation for published version (APA):

Adawy, A., Amghouz, Z., van Hest, J. C. M., \& Wilson, D. A. (2017). Sub-micron polymeric stomatocytes as promising templates for confined crystallization and diffraction experiments. Small, 13(28), 1-8. [1700642]. https://doi.org/10.1002/smll.201700642

DOI:

10.1002/smll.201700642

Document status and date:

Published: 13/07/2017

\section{Document Version:}

Accepted manuscript including changes made at the peer-review stage

\section{Please check the document version of this publication:}

- A submitted manuscript is the version of the article upon submission and before peer-review. There can be important differences between the submitted version and the official published version of record. People interested in the research are advised to contact the author for the final version of the publication, or visit the $\mathrm{DOI}$ to the publisher's website.

- The final author version and the galley proof are versions of the publication after peer review.

- The final published version features the final layout of the paper including the volume, issue and page numbers.

Link to publication

\section{General rights}

Copyright and moral rights for the publications made accessible in the public portal are retained by the authors and/or other copyright owners and it is a condition of accessing publications that users recognise and abide by the legal requirements associated with these rights.

- Users may download and print one copy of any publication from the public portal for the purpose of private study or research.

- You may not further distribute the material or use it for any profit-making activity or commercial gain

- You may freely distribute the URL identifying the publication in the public portal.

If the publication is distributed under the terms of Article 25fa of the Dutch Copyright Act, indicated by the "Taverne" license above, please follow below link for the End User Agreement:

www.tue.nl/taverne

Take down policy

If you believe that this document breaches copyright please contact us at:

openaccess@tue.nl

providing details and we will investigate your claim. 


\section{WILEY-VCH}

DOI: 10.1002/ ((please add manuscript number))

Article type: ((Full Paper))

Title ((Submicron polymeric stomatocytes as promising templates for confined crystallization and diffraction experiments))

Alaa Adawy,* Zakariae Amghouz, Jan C. M. van Hest and Daniela A. Wilson*

Dr. A. Adawy: Institute for Molecules and Materials, Radboud University, 6525 AJ Nijmegen, The Netherlands; current address: Department of Drug Design, Groningen Research Institute of Pharmacy, University of Groningen, 9700 AD Groningen, The Netherlands

E-mail: a.adawy@rug.nl

Dr. Z. Amghouz: HRTEM Laboratory, Scientific-Technical Services, University of OviedoCINN, Oviedo, 33006, Spain; current address: Department of Materials Science and Metallurgical Engineering, University of Oviedo, Campus Universitario, 33203 Gijón, Spain Prof.dr. J.C.M. van Hest: Institute for Molecules and Materials, Radboud University, 6525 AJ Nijmegen, The Netherlands; current address: Eindhoven University of Technology, Department of Biomedical Engineering and Department of Chemical Engineering \&Chemistry, Lab Bio-organic chemistry, POB 513, NL-5600 MB Eindhoven, The Netherlands.

Dr. D.A.Wilson: Institute for Molecules and Materials, Radboud University, 6525 AJ

Nijmegen, The Netherlands

E-mail: $\underline{\text { d.wilson@science.ru.nl }}$

Keywords: Confinement, crystallization, polymeric stomatocytes; electron diffraction, TEM

Abstract: We investigated the possibility of using submicron polymeric stomatocytes to effectuate confined crystallization of inorganic compounds. These bowl-shaped polymeric compartments facilitate confined crystallization while their glassy surfaces provide their crystalline cargos with convenient shielding from the electron beam's harsh effects during transmission electron microscopy experiments. Stomatocytes host the growth of a single nanocrystal per nano-cavity, and the electron diffraction experiments revealed that their glassy membranes do not interfere with the diffraction patterns obtained from their crystalline cargos. Therefore, we expect that the encapsulation and crystallization within these compartments could be considered as a promising template (nano-vials) that hold and protect nanocrystals and protein clusters from the direct radiation damage before data acquisition, while they are 


\section{WILEY-VCH}

examined by modern crystallography methodologies such as serial femtosecond crystallography.

\section{Introduction}

Crystallization is a vital tool for assembling regularly repeated entities of (in)organic compounds or biological macromolecules or their complexes which are then characterized by modern crystallography methodologies to eventually determine their 3D structure down to the atomic scale.[1] Nowadays, (macromolecular) crystallography has improved drastically, and allows the collection of diffraction data from tiny crystals, ${ }^{[2]}$ clusters and single particles. ${ }^{[3,4,5]}$ However, reducing the radiation damage during data acquisition for biological crystals is challenging. Although cryo-cooling is usually used to flash-freeze the crystals so that they can resist radiation damage for relatively longer exposure periods, local atomic rearrangements that take place due to unavoidable radiation damage prevent most studies to proceed to a significant level.[6] More importantly, the cryo-structure of a specific protein does not always represent its real structure at equilibrium, because many degrees of freedom are suppressed at cryotemperatures. ${ }^{[7]}$ More attention is currently drawn toward studying protein dynamics using time resolved serial femtosecond crystallography (SFX) which is performed at room temperature in order to detect all conformational changes a protein encounter to perform its function. ${ }^{[8]}$ Confined crystallization or even simple encapsulation in compartments that do not interfere with data acquisition could assist in providing these sensitive crystals or protein clusters with the required shield against radiation that, in turn, increases significantly during room temperature diffraction data collection.

Confined crystallization is a line of research that has emerged in two directions, one of which aims to further understand the very early stages of nucleation and crystal growth at a size scale 


\section{WILEY-VCH}

[2, 9] The other applied oriented research direction aims to crystallize confined uniformly oriented inorganic and organic compounds with the required submicron particle size, crystal habit and polymorphic form. ${ }^{[10]}$ These studies were conducted by utilizing naturally existing macromolecular cages (Ferritin), ${ }^{[11]}$ and synthetic structures such as organic cages,[12] mesoporous silica, ${ }^{[13]}$ organized organic templates and surfaces (Langmuir monolayers),[14] porous anodic alumina,[15] organic polymers, ${ }^{[16]}$ nanoporous (block co-)polymers, ${ }^{[17]}$ polymer micro-gels,[18] and phospholipid vesicles (liposomes). ${ }^{[19]}$

For macromolecules, confined crystallization was explored in lipidic cubic phases, and porous bioglass and was shown to affect the protein solubility and decrease the nucleation energy barrier. ${ }^{[20]}$ However, complete encapsulation and growth of protein crystals were only reported using relatively larger liposomes $(20-60 \mu \mathrm{m}){ }^{[21]}$ liposomes have minor control over crystal morphology due to their flexible membrane that can be easily stretched by the encapsulated nanocrystals. A synthetic alternative to liposomes is the polymeric vesicles widely known as polymersomes that possess more stability and rigidity in their membranes.[22] So far, polymersomes have been proved to be a versatile platform and were explored for several medical applications.[23] They are assembled from amphiphilic block copolymers and can undergo shape transformations to several morphologies such as discs, rods, tubes and bowlshaped stomatocytes.[24, 25] The stomatocytes offer additional properties compared to the ordinary spherical polymersomes by providing an extra compartment, a nanocavity, which is connected to the outer environment via an adjustable opening.[25, 26]

Herein, we show that these stomatocytes can serve as confined hosts for nanocrystals grown by the simple batch crystallization method (Scheme 1). At this nanoscale, convective mixing 
does not occur and thus growth in these compartments is expected to result in diffusion-limited crystal growth, which is the effective route to grow perfect crystal.

\section{WILEY-VCH}

[27] The crystallinity of the resultant nanocrystals was confirmed by electron diffraction. The amorphous nature of the polymeric compartments prevents background diffraction interference with the diffraction pattern of the confined crystals. Although the encapsulated crystals were not flash frozen or cryoprotected, they could resist the radiation damage caused by the electron beam for a much longer time compared to the un-encapsulated crystals. This suggests the possibility of using these glassy stomatocytes as nano-vials to encapsulate nanocrystals or protein clusters during their characterization by crystallography methodologies with much less radiation damage and thus more reliable structural information. ${ }^{[4,28]}$

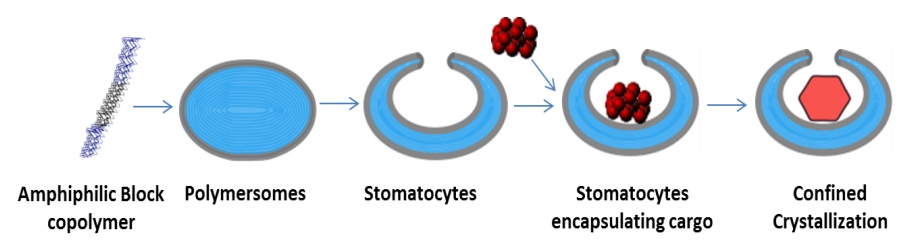

Scheme 1. The route followed to utilize polymeric vesicles for confined crystallization. Polymersomes assembly, their shape transformation to stomatocytes, followed by cargo encapsulation and crystallization.

\section{Results}

In order to prepare the stomatocytes, a solution of the amphiphilic block copolymer poly(ethylene glycol)-b-polystyrene ( $\left.\mathrm{PEG}_{44}-\mathrm{PS}_{160}\right)$ was dissolved in organic solvent. (tetrahydrofuran (THF) \& 1,4 dioxane) set at several ratios to allow for facile vesicle formation and to preserve integrity in case proteins were to be encapsulated. ${ }^{[29]}$ The assembly of 
polymersomes was stimulated by the controlled slow addition of water into this mixture that was set to stir. After dialysis against water, reverse dialysis in $50 \%$ organic solvent and subsequent quenching in water, the vesicular structures underwent an osmotic shock and transformed to bowl-shaped polymeric stomatocytes. ${ }^{[30]}$

\section{WILEY-VCH}

Inorganic compounds that crystallize in different crystalline systems were chosen for the confined crystallization experiments. We found that stomatocytes with inner compartments exceeding $200 \mathrm{~nm}$ in diameter efficiently facilitated crystallization (Figure S1-S3). Additionally, stomatocytes with openings $\leq 40 \mathrm{~nm}$ in diameter encapsulated and entrapped the supersaturated solutions of the tested compounds (Figure S4) (KDP, $\mathrm{NaCl}, \mathrm{NaClO}_{3}$ and $\left.\left(\mathrm{NH}_{4}\right)_{2} \mathrm{SO}_{4}\right)$ which thereafter underwent batch crystallization when incubated at $4^{\circ} \mathrm{C}$. This was confirmed by their morphology, elemental analyses and diffractivity, investigated via dry Transmission Electron Microscopy (dry-TEM), Energy Dispersive X-ray (EDX) mapping, and Selected Area Electron Diffraction (SAED), respectively (Figure1-4). SAED and associated indexing also revealed that the polymorphism was preserved for $\left(\mathrm{NH}_{4}\right)_{2} \mathrm{SO}_{4}$ that can crystallize in 2 polymorphic forms, (Figure 2).

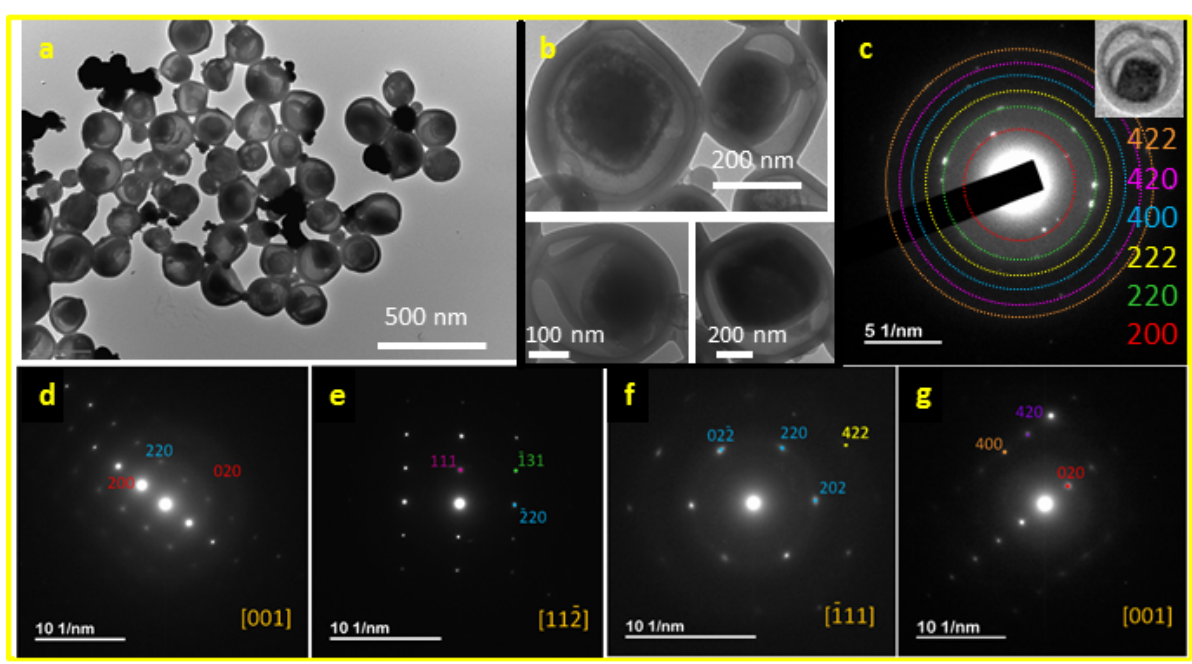


Figure 1. NaCl crystals grown within the stomatocytes. As bright field dry-TEM micrographs show (a,b), the crystals grew easily inside the stomatocytes with inner compartments $\geq 200 \mathrm{~nm}$ in diameter to their full capacity. The crystalline nature of the confined $\mathrm{NaCl}$ crystals is confirmed using SAED for several crystals (c) and for individual crystals examined along different zone-axes (d-g). The indexing of the ED patterns showed the observed $\mathrm{d}_{\mathrm{hkl}}$-spacing corresponding to the FCC crystal structure (space group Fm-3m and $a=5.6402 \AA$; ICSD PDF4: 05-0628)

\section{WILEY-VCH}
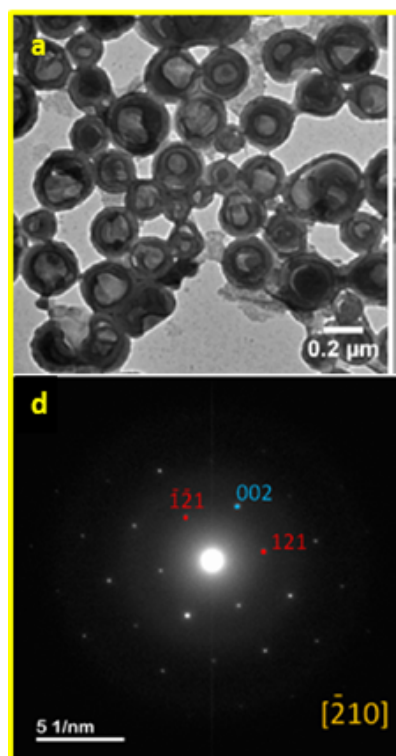

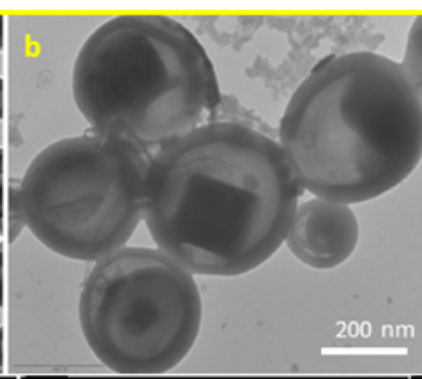

e

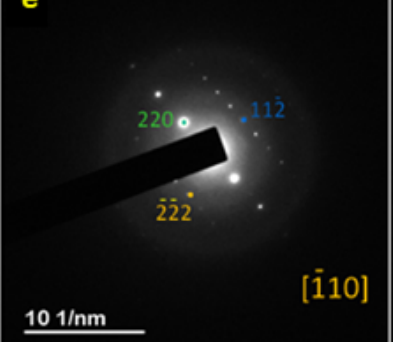

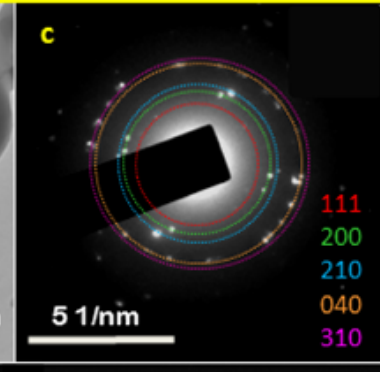

f

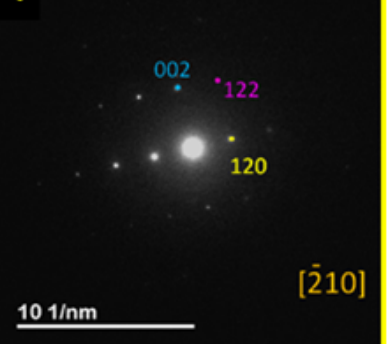

Figure 2. (NH4) ${ }_{2} \mathrm{SO}_{4}$ crystals grown within the stomatocytes as shown by bright field dryTEM micrographs (a,b). The crystalline nature of the confined crystals was confirmed using SAED for several $\left(\mathrm{NH}_{4}\right)_{2} \mathrm{SO}_{4}$ crystals (c) and taken from different zone-axes for individual $\left(\mathrm{NH}_{4}\right)_{2} \mathrm{SO}_{4}$ crystals (d-f). The indexing of SAED patterns showed that $\left(\mathrm{NH}_{4}\right)_{2} \mathrm{SO}_{4}$ phase crystallizes in orthorhombic space group Pnam and $a=7.762, b=10.612$, and $c=5.979 \AA$ (ICSD: 200905)

Although $\mathrm{KDP}$ and $\mathrm{NaClO}_{3}$ crystals were more sensitive to the electron beam, yet the EDX mapping and SAED confirmed the crystalline content of the encapsulated crystals (Figures 3-4 


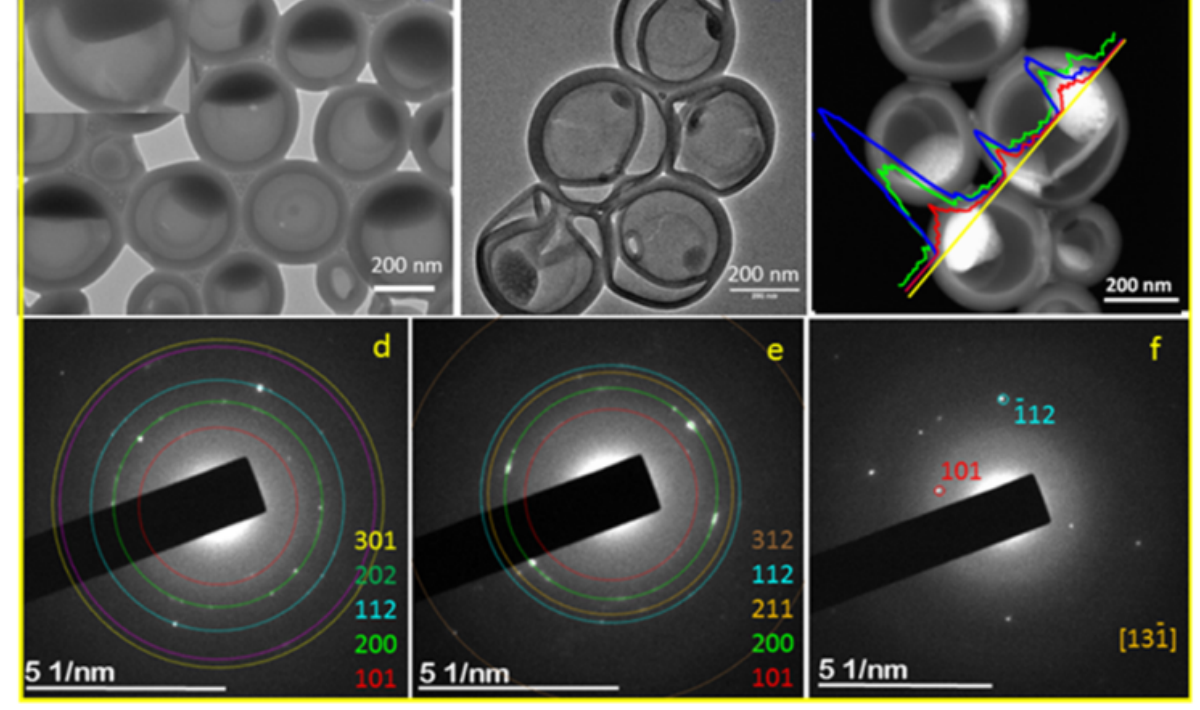

Figure 3. Bright field dry-TEM micrographs for stomatocytes encapsulating KDP melting

\section{WILEY-VCH}

crystals (a,b). Dark field-STEM micrograph with EDX line-scan analysis (c) across these crystals revealed their high content of the main elements: phosphorous (blue), oxygen (green) and potassium (red). Although they could be considered as a poorly-diffracting crystals compared to those of other compounds, SAED patterns indexing (d-e) and diffraction for an individual crystal along its zone axis (f) revealed their tetragonal structure with space group $I$ 42d and $a=7.448$ and $c=6.977 \AA$ (ICSD PDF4: 031-1030)

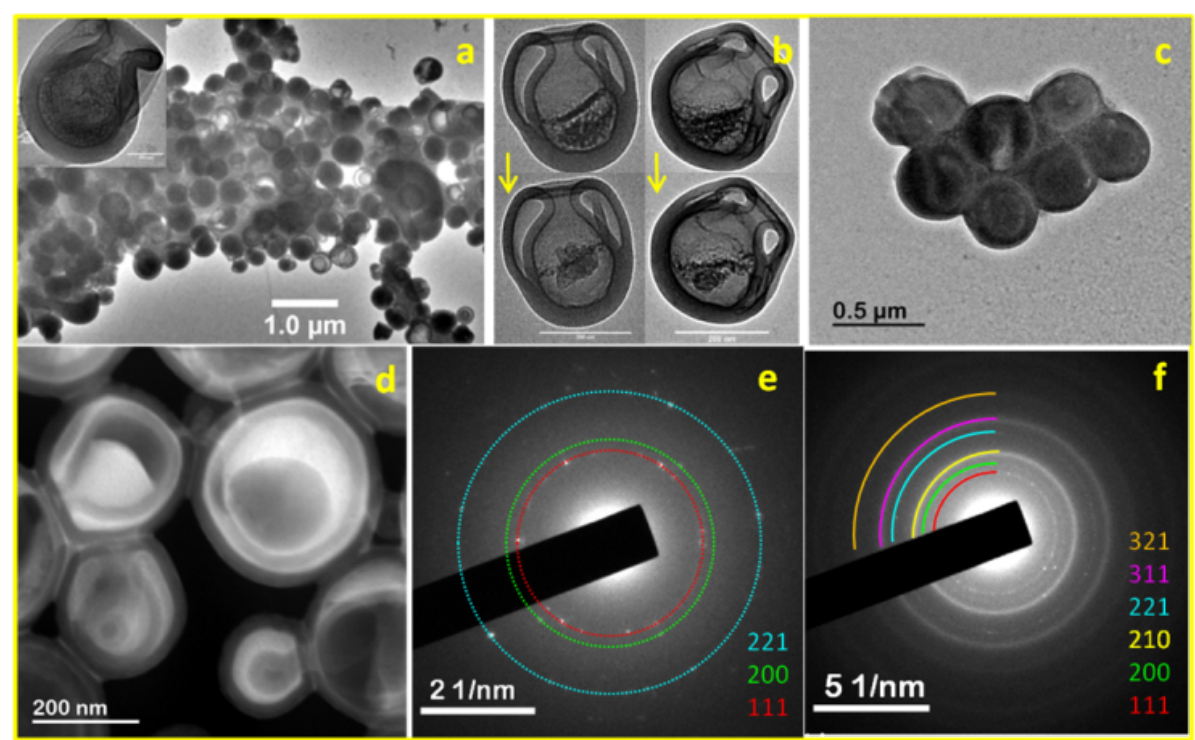

Figure 4. Bright-field (a,c) and dark-field (d) dry-TEM micrographs for stomatocytes encapsulating $\mathrm{NaClO}_{3}$. As shown in (b), the crystals were melting directly when exposed to the electron beam. However, their SAED (e-f) showed their cubic structure with space group $\mathrm{P} 2{ }_{1} 3$ and $\mathrm{a}=6.57 \AA$ (ICSD PDF4: 01-0908) 
in general much less than that of those grow in the remnant solution outside the stomatocytes, which evaporated instantaneously upon exposure to the electron beam. Therefore, we investigated in depth if the nanocavity of the stomatocytes would provide the encapsulated nanocrystals with the adequate protection if they are directly examined by, for instance, in situ serial crystallography. For that, a comparative inspection was performed to determine the effect of electron beam exposure on encapsulated and exposed crystals. We found that the encapsulated nanocrystals could withstand the radiation damage induced by high-dose electron beam to relatively higher threshold compared to unprotected crystals of even $10 \times$ larger sizes when exposed to the same dose concentration (Figure 5). This confirms the shielding effect

\section{WILEY-VCH}

that these glassy compartments can provide for their (non) crystalline cargos.

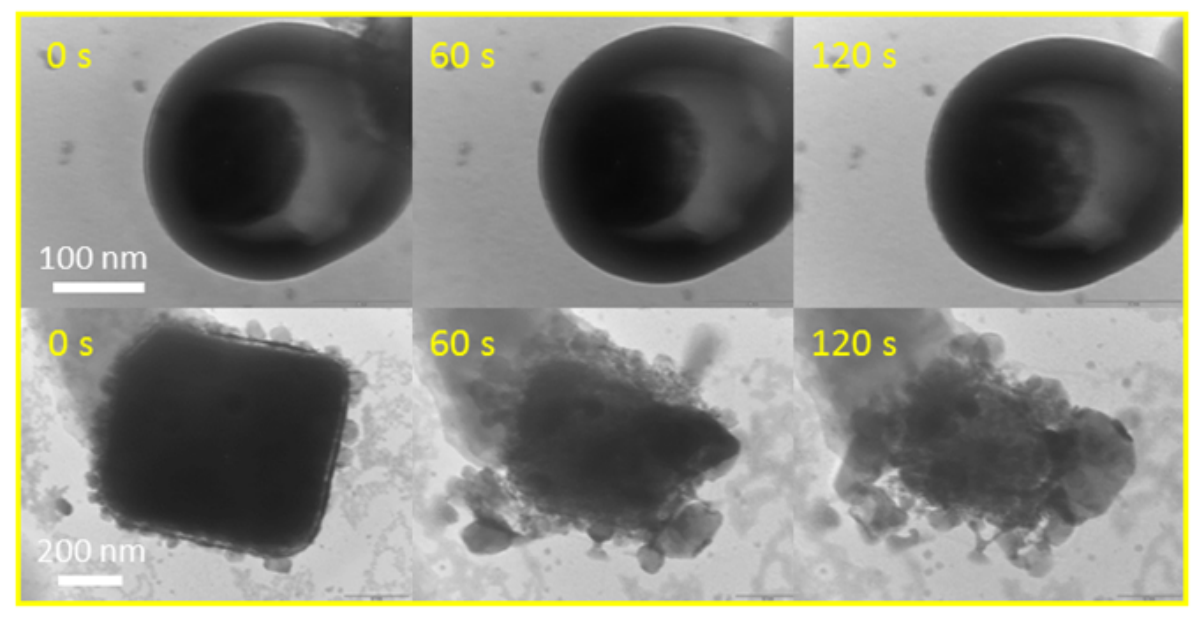

Figure 5. Timeline for (NH4) ${ }_{2} \mathrm{SO}_{4}$ crystals under prolonged exposure to the electron beam of TEM. The upper lane shows the shielding effect of the polymeric membrane of the stomatocytes against the damage that the encapsulated crystal could encounter if it was subjected directly to the electron beam. The lower lane shows the 10 times larger, but unshielded crystal which could not withstand the radiation damage and evaporated dramatically.

\section{Discussion}


The results show that the polymeric stomatocytes provide means to separate the compartment assembly from cargo encapsulation. For crystallization, their opening allow for the solution exchange, while nucleation and growth of nanocrystals take place within their uniformly rounded inner compartments. The capability of these nanocapsules to host the growth of nanocrystals is represented here by the growth of nanocrystals from the four inorganic compounds used in this study The performed electron diffraction experiments for the crystalline cargo have not shown any background diffraction caused by their compartments. More importantly, the stomatocyte's membrane provides the cargo with extra protection against the damaging effect of the electron beam.

Separating the compartments self-assembly and shape transformation from their cargo encapsulation provides a practical alternative to the complications that was encountered when

\section{WILEY-VCH}

attempts were made to encapsulate the compound to be crystallized in vesicles during their self-assembly procedure. Although we could encapsulate protein [Hen Egg-White lysozyme (HEWL)] and KDP inside PEG-PS polymersomes during their self-assembly (Figure S8), we found that adding inorganic compounds that possess relatively high solubility values into the aqueous phase led to polymer precipitation [as was the case with $\left.\left(\mathrm{NH}_{4}\right)_{2} \mathrm{SO}_{4}\right)$ ] or the assembly of structures extending from the nanoscopic up to macroscopic scale, hexagonally-packed hollow hoops (HHHs), beads on a string and tubules [as was the case with $\mathrm{NaCl}$ and $\mathrm{NaClO}_{3}$ ]

(Figures S9 \& S10). The resultant relatively large size scale of the structures was also observed when higher salt concentrations were used in the dialysis (Figure S11). Although the formation of these structures is understandable (Supplementary note1), and some of them induced the growth of nanocrystals, they did not yield a mono-disperse high population of one crystalline 
form with narrow size distribution.

Stomatocytes beat liposomes in the rigidity of their membrane, which provide them with a good control over their cargo's crystal morphology and final size. Another advantage of stomatocytes is their inherent opening which acts as a valve that allow for entrapping the encapsulated compounds and possible solution exchange that is necessary for crystal growth. We observed that nanocrystals grow to sizes that would not have been possible if their growth was only mediated by the initial solution volume entrapped in the stomatocytes. In our experiments, we found that the diameter of the stomatocytes' nanocavities has to be preferentially around $200 \mathrm{~nm}$ to allow for the nucleation of small inorganic compounds. At this size scale, our attempts to encapsulate HEWL was also successful (Figures S4 \& S8), however, we could not detect protein crystal growth even with HEWL labelled with a compound that enhances nucleation and crystals characterization (visibility)

9

\section{WILEY-VCH}

[31, 32] (Figure S12). This might be attributed to the size restriction imposed by the stomatocytes, which could have hindered the onset of HEWL nucleation. For (in-)organic compounds, the critical size of the nuclei is in the order of tens of nanometers, but for macromolecules, this extends to few hundreds of nanometers depending on their molecular size. ${ }^{[2]}$ Recent studies have shown that nucleation of 3D protein crystals is mediated by a twostep (non-classical) nucleation mechanism in which protein entities first aggregate to form metastable mesoscopic dense clusters containing amorphous solid particles before nuclei appear. ${ }^{[33]}$ For HEWL crystallization, the $100-150 \mathrm{~nm}$ clusters should undergo a sort of Ostwald ripening in which small clusters dissolve to redeposit on larger pre-existing clusters, 
stomatocytes will guarantee that they can be tested in their single molecular rather than crystalline form. ${ }^{[5]}$ As our investigations revealed, the stomatocytes which surround their cargos with two layers of their polymeric membrane provide them with adequate shielding from possible radiation damage during electron diffraction experiments, while no background diffraction from these glassy compartments is expected to interfere with the obtained data from the encapsulated cargos.

\section{Conclusions and outlook}

We show the capability of growing nanocrystals in confined nanoscale PEG-PS stomatocytes. The main advantage of encapsulating nanocrystals in such compartments is the protection they provide to their cargos during their characterization. The suggested approach could provide a basis for a facile methodology in which a supersaturated solution of any (macro-)molecule under study can be vigorously mixed with polymeric stomatocytes suspended in small volume of adequate aqueous media to induce their encapsulation in the stomatocytes nano-cavities. Afterwards, batch crystallization can be effectuated if the suspension is incubated at a suitable temperature for nucleation and crystal growth. The

\section{WILEY-VCH}

resultant glassy nano-vials, containing (non-)crystalline cargos suspended in an aqueous media, can be infused in a liquid jet injector for a serial femtosecond crystallography (SFC) experimental setting that expedites “diffraction before destruction".[35] We expect that these stomatocytes could be appropriate hosting capsules for characterization of crystallized smaller entities of peptides and organic compounds as well as molecular or cluster entities of larger macromolecules.

\section{Experimental Section}

Materials: All reagents and chemicals were of reagent grade and used without further purification. Hen egg- 
white lysozyme [HEWL] (cat. no. L6876) was purchased from Sigma-Aldrich and also used without further purification. Fluorescent dye DY-632-01 NHS ester (C14H49N3O14S3Na2; MW = 950.03 g mol-1, Dyomics) was used to label HEWL as thoroughly described elsewhere.[32] Ultra-pure MilliQ water was obtained with MilliQ QPOD purification system (18.2 M $\Omega$ ) and was used for the self-assembly of polymersomes and for the dialysis experiments and for the preparation of all crystallization solutions. Spectra/Por ${ }^{\circledR}$ Dialysis Membrane MWCO: 12-14,000 was used for dialysis of polymersomes and their shape transformation into stomatocytes. Ultra-free-MC centrifugal filters $0.22 \mu \mathrm{m}$ were purchased from Millipore.

Characterization techniques. NMR spectra were recorded to calculate the degree of polymerization of the block co-polymer poly(ethylene glycol) 44 -b-polystyrene ${ }_{160}\left(\mathrm{PEG}_{44}-\mathrm{PS}_{160}\right)$, NMR experiments were performed on a Varian Inova 400 spectrometer with $\mathrm{CDCl}_{3}$ as a solvent and TMS as internal standard. Gel Permeation Chromatography (GPC) was performed on a Shimadzu Prominence GPC system equipped with a PL gel $5 \mu \mathrm{m}$ mixed D column (Polymer Laboratories) and differential refractive index and UV (254 nm) detectors. THF was used as an eluent with a flow rate of $1 \mathrm{~mL} / \mathrm{min}$. Polystyrene standards in the range of 580 to 377,400 Da were used for calibration. Dynamic light scattering (DLS) analyses were performed on a Malvern Zetasizer Nano S equipped with a He-Ne (633 nm, $4 \mathrm{~mW}$ ) laser and an Avalanche photodiode detector at an angle of $170^{\circ}$. DLS data were processed on a Dispersion Technology Software (Malvern Instruments).

Three Transmission Electron Microscopes (TEM) were used in our experiments: 1. JEOL 1010 microscope equipped with a CCD camera operating at an acceleration voltage of $55 \mathrm{kV}$. This microscope was used for routine inspections. Additionally, the low voltage allowed the inspection of polymersomes and stomatocytes containing sensitive crystals (KDP); 2. JEOL TEM 2100 operating at $200 \mathrm{kV}$ and equipped with two

\section{WILEY-VCH}

Gatan cameras: the high-quality Gatan 833 Orius. These cameras were used for the dry and cryo-inspection, respectively. STEM detector with the Bruker EDS system element analysis was used for EDX mapping; and 3. JEOL JEM-2100F field - emission gun TEM operating at an accelerating voltage of $200 \mathrm{kV}$ and equipped with an ultra-high resolution pole-piece that provides a point-resolution better than $0.19 \mathrm{~nm}$. It is also equipped with STEM control unit (Gatan), EDX detector (Oxford Instruments, SDD 80 mm2), CCD camera (14-bit Gatan Orius SC600), and bright-field (BF) and HAADF detectors (JEOL). This microscope was used for EDX line-scan and mapping, dark-field (HAADF) imaging and Selected Area Electron Diffraction (SAED). 
solutions on a carbon-coated $\mathrm{Cu}$ grid (200 mesh, EM science) followed by air- drying. For Cryo-TEM, no dilutions were performed and the sample was directly vitrified in the fully automated vitrification robot FEI Vitrobot $^{\mathrm{TM}}$ Mark IV. Processing and analysis of the TEM images was performed with ImageJ, a program developed by the NIH and available as public domain software at http://rsbweb.nih.gov/ij/. SAED patterns analysis were performed by means of Gatan Digital Micrograph software.

Experimental procedures.

a. Synthesis of the block-copolymer: Poly(ethylene glycol)-polystyrene block co-polymer was synthesized by using atom-transfer radical polymerization (ATRP) as explained elsewhere.[36] SEC: $\mathrm{Mn}=16.2 \mathrm{~kg} / \mathrm{mol}$ and $\mathrm{Đ}=1.03 ; \mathrm{NMR}: \mathrm{DPn}=160$

b. Self-assembly of polymersomes and their shape transformation into stomatocytes:10 mg of PEG44-PS160 was dissolved in a mixture of THF and 1,4-dioxane (1 mL, 4:1 ratio) in a $5 \mathrm{ml}$ capped vial equipped with a magnetic stirrer and closed with a rubber septum. After the polymer completely dissolved, $1 \mathrm{~mL}$ of MilliQ water was syringe-pumped into the organic phase at a rate of $1 \mathrm{ml} / \mathrm{hr}$. The solution which was set to stir until it turned cloudy, revealing the formation of the polymersomes. The suspension was then transferred in a dialysis bag (SpectroPor, molecular weight cut-off $12-14 \mathrm{KDa}$ ) and dialyzed against water. The dialysis water was replaced after 1, 12 and 24 hrs. Stomatocytes were obtained, which were used for the comparison with the larger stomatocytes mentioned below.

c. Formation of stomatocytes out of disc-like polymersomes: $10 \mathrm{mg}$ of PEG44-PS160 was dissolved in 1mL of a mixture of organic solvent with a THF to dioxane ratio of 1:4. To this mixture, 1.5ml of MilliQ water was syringe pumped at $1 \mathrm{ml} / \mathrm{hr}$. The cloudy suspension was afterwards transferred to a dialysis bag and dialyzed against MilliQ water which was replenished after 1, 12 and 24 hrs. The obtained discs were treated by means of reverse dialysis for $1 \mathrm{hr}$ in equal portions of water and organic solvent with THF:dioxane at 1:4. The formed

\section{WILEY-VCH}

stomatocytes were quenched in water and concentrated back to their initial volume.

d. Crystallization within the premade stomatocytes: In order to induce the encapsulation of different cargo, the stomatocytes were vigorously mixed with the respective supersaturated solution of every inorganic compound [ $\mathrm{NaCl}(36 \mathrm{~g} \%), \mathrm{NaClO}_{3}(100 \mathrm{~g} \%),\left(\mathrm{NH}_{4}\right)_{2} \mathrm{SO}_{4}(75 \mathrm{~g} \%)$ and $\mathrm{KH}_{2} \mathrm{PO}_{4}(25.3 \mathrm{~g} \%)$ ] and the crystallization solution of HEWL (10-50 mg/ml supersaturated with $0.5-1 \mathrm{M} \mathrm{NaCl})$ used in this study. 
Afterwards, the resulted suspensions were kept at $4^{\circ} \mathrm{C}$ to assist the crystallization of the encapsulated solutions and to avoid the precipitation of the stomatocytes.

e. Simultaneous polymersome assembly and inorganic compound encapsulation: Supersaturated solutions of $\mathrm{NaCl}(36 \mathrm{~g} \%), \mathrm{NaClO}_{3}(100 \mathrm{~g} \%),(\mathrm{NH} 4)_{2} \mathrm{SO}_{4}(75 \mathrm{~g} \%)$ and $\mathrm{KH}_{2} \mathrm{PO}_{4}(25.3 \mathrm{~g} \%)$ were prepared in water and used as the aqueous medium $(1 \mathrm{~mL})$ to induce the self-assembly of $10 \mathrm{mg}$ of $\mathrm{PEG}_{44}-\mathrm{PS}_{160}$ dissolved in a mixture of THF and 1,4-dioxane (1 mL, 4:1 ratio) in a $5 \mathrm{ml}$ capped vial equipped with a magnetic stirrer and closed with a rubber septum. After the completion of syringe pumping at a flow rate of $1 \mathrm{ml} / \mathrm{hr}$, the suspension was dialyzed against the respective undersaturated solution overnight [NaCl (18 g\%), $\mathrm{NaClO}_{3}(50 \mathrm{~g} \%),\left(\mathrm{NH}_{4}\right)_{2} \mathrm{SO}_{4}(37 \mathrm{~g} \%)$ and $\mathrm{KH}_{2} \mathrm{PO}_{4}(13 \mathrm{~g} \%)$. Dialysis also induced osmotic stress over the membrane since the vesicles or assemblies were not quenched first to vitrify the membrane.

f. Simultaneous polymersome assembly and HEWL encapsulation: $1 \mathrm{~mL}$ of HEWL crystallization solution of up to $50 \mathrm{mg} / \mathrm{ml}$ concentration supersaturated with $0.5-1 \mathrm{M} \mathrm{NaCl}$ was used as the aqueous medium which was syringe pumped into a $10 \mathrm{mg} / \mathrm{mL} \mathrm{PEG}_{44}-\mathrm{PS}_{160}$ solution of THF and 1,4-dioxane (1 mL, 1:1 ratio) in a $5 \mathrm{ml}$ capped vial equipped with a magnetic stirrer and closed with a rubber septum. After the completion of syringe pumping, the suspension was dialyzed against buffer which was replenished after 1, 12 and 24 hrs.

\section{Supporting Information}

Supporting Information is available from the Wiley Online Library or from the author.

\section{Acknowledgements}

AA thanks Dr. Y. Men \& L. Abdelmohsen for the help with PEG-PS polymerization; G-J Janssen \& Dr. E. Pierson for the guidance with TEM measurements executed at the Department of General instrumentation and Dr. P. Tinnemans for the confirmatory PXRD measurements for the initial compounds; JvH, DAW and AA acknowledge the support from the European Research Council under the European Union's Seventh Framework Programme (FP7/2007-20012)/ERC-StG 307679 “StomaMotors” and the support from the Ministry of Education, Culture and Science (Gravitation program 024.001.035).

\section{WILEY-VCH}

Received: ((will be filled in by the editorial staff))

Revised: ((will be filled in by the editorial staff)) Published online: ((will be filled in by the editorial staff)) 


\section{References}

[1] a) A. McPherson, Crystallization of biological macromolecules. Cold Spring Harbor Laboratory Press: 1999; b) J. J. De Yoreo, P. G.Vekilov, Reviews in mineralogy and geochemistry 2003, 54, 57; c) A. Chernov , Modern Crystallography III. Springer-Verlag: Berlin, 1984.

[2] Q. Jiang, M. D. Ward, Chem. Soc. Rev. 2014, 43, 2066.

[3] a) C. Riekel, M. Burghammer, G. Schertler, Curr. Opin. Struct. Biology 2005, 15, 556; b) P. Fromme, J. C. H. Spence, Curr. Opin. Struct. Biology 2011, 21, 509; c) M. S. Hunter, D. P. DePonte, D. Shapiro, R. A. Kirian, X. Wang, D. Starodub, S. Marchesini, U. Weierstall, R. B. Doak, J. C. Spence, Biophys. journal 2011, 100, 198; d) R. Neutze, G. Brändén, G. F. Schertler, Curr. Opin. Struct. Biology 2015, 33, 115; e) K. Ayyer, G. Geloni, V. Kocharyan, E. Saldin, S. Serkez, O. Yefanov, I. Zagorodnov, Struct. Dynamics 2015, $2,041702$.

[4] a) R. Henderson, Proceedings: Biological Sciences 1990, 6; b) W. P. Burmeister, Acta Crystallogr. D 2000, 56, 328-341.

[5] B. Halle, P. Natl. Acad. Sci. USA 2004, 101, 4793.

[6] a) P. Edlund, H. Takala, E. Claesson, L. Henry, R. Dods, H. Lehtivuori, M. Panman, K. Pande, T. White, T. Nakane, O. Berntsson, E. Gustavsson, P. Båth, V. Modi, S. RoyChowdhury, J. Zook, P. Berntsen, S. Pandey, I. Poudyal, J. Tenboer, C. Kupitz, A. Barty, P. Fromme, J. D. Koralek, T. Tanaka, J. Spence, M. Liang, M. S. Hunter, S. Boutet, E. Nango, K. Moffat, G. Groenhof, J. Ihalainen, E. A. Stojković, M. Schmidt, S. Westenhoff, Sci. Reports 2016, 6, 35279; b) W. Liu, D. Wacker, C. Wang, E. Abola, V. Cherezov, Philos. Trans. R. Soc. B, Biol. Sci. 2014, 369, 20130314.

[7] Y. Diao, T. Harada, A. S. Myerson, T. Alan Hatton, B. L. Trout, Nat. Mater. 2011, 10 , 867.

[8] a) S. Mann, Biomineralization: principles and concepts in bioinorganic materials chemistry. Oxford University Press: 2001; Vol. 5; b) W. L. Noorduin, A. Grinthal, L. Mahadevan, J. Aizenberg, Science 2013, 340, 832.

[9] R. M. Kramer, C. Li, D. C. Carter, M. O. Stone, R. R. Naik, Journal of the American Chemical Society 2004, 126, 13282; b) M. A. Kostiainen, P. Hiekkataipale, A. Laiho, V. Lemieux, J. Seitsonen, J. Ruokolainen, P. Ceci, Nat. Nano. 2013, 8, 52.

[10] N. Herron, Y. Wang, M. M. Eddy, G. D. Stucky, D. E. Cox, K. Moller, T. Bein, J. Am. Chem.Soc. 1989, 111, 530.

[11] A. Schreiber, I. Ketelsen, G. H. Findenegg, Phys. Chem. Chem. Phys. 2001, 3, 1185.

[12]B. R. Heywood, S. Mann, J. Am. Chem.Soc. 1992, 114, 4681.

[13] a) R. Redón, A. Vázquez-Olmos, M. E. Mata-Zamora, A. Ordóñez-Medrano, F. RiveraTorres, J. M. Saniger, J. Colloid Interface Sci. 2005, 287, 664; b) Q. Jiang, C. Hu, M. D. Ward, J. Am. Chem.Soc. 2013, 135, 2144.

[14] P. Calvert, MRS Bulletin 1992, 17, 37. 
[16] Y. Diao, K. E. Whaley, M. E. Helgeson, M. A. Woldeyes, P. S. Doyle, A. S. Myerson, T. A. Hatton, B. L. Trout, J. Am. Chem.Soc.2012, 134, 673.

[17] a) S. Bhandarkar, A. Bose, J. Colloid Interface Sci. 1990, 135, 531; b) D. Cipolla, H. Wu, S. Salentinig, B. Boyd, T. Rades, D. Vanhecke, A. Petri-Fink, B. Rothin-Rutishauser, S. Eastman, T. Redelmeier, I. Gonda, H. K. Chan, RSC Advances 2016, 6, 6223.

[18] a) S. Tanaka, S. Egelhaaf, W. Poon, arXiv preprint cond-mat/0309373 2003; b) C. N. Nanev, E. Saridakis, N. E. Chayen, Sci. Reports 2017, 7, 35821.

[19] Y. Yamashita, M. Oka, T. Tanaka, M. Yamazaki, Biochim. Biophys. Acta, Biomembr. 2002, 1561, 129.

[20]a) B. M. Discher, Y. Y. Won, D. S. Ege, J. C. Lee, F. S. Bates, D. E. Discher, D. A. Hammer, Science 1999, 284, 1143; b) D. E. Discher, A. Eisenberg, A., Science 2002, 297, 967.

[21] a) P. Tanner, P. Baumann, R. Enea, O. Onaca, C. Palivan, W. Meier, Accounts of Chemical Research 2011, 44, 1039; b) D. E. Discher, F. Ahmed, Annu. Rev. Biomed. Eng. 2006, 8, 323; c) D. A. Hammer, G. P. Robbins, J. B. Haun, J. J. Lin, W. Qi, L. A. Smith, P. P. Ghoroghchian, M. J. Therien, F. S. Bates, Faraday discuss. 2008, 139, 129; d) R. P. Brinkhuis, F. P. Rutjes, J. C. van Hest, Polym. Chem. 2011, 2, 1449; e) D. E. Discher, V. Ortiz, G. Srinivas, M. L. Klein, Y. Kim, D. Christian, S. Cai, P. Photos, F. Ahmed, Prog. Polym. Sci. 2007, 32, 838; f) O. Onaca, R. Enea, D. W. Hughes, W. Meier, Macromol. Biosci. 2009, 9, 129; g) F. Meng, Z. Zhong, J. Phys. Chem. Letters 2011, 2, 1533; h) J. S. Lee, J. Feijen, J.Controlled Release 2012, 161, 473

[22] a) R. S. M. Rikken, H. Engelkamp, R. J. M. Nolte, J. C. Maan, J. C. M. van Hest, D. A. Wilson, P. C. M. Christianen, Nat. Comm. 2016, 7, 12606; b) K. T. Kim, J. Zhu, S. A. Meeuwissen, J. J. Cornelissen, D. J. Pochan, R. J. Nolte, J. C. M. van Hest, J. Am. Chem. Soc. 2010, 132, 12522; c) W. Gózdz, Langmuir 2004, 20, 7385; d) S. A. Meeuwissen, K. T. Kim, Y. Chen, D. J. Pochan, J. C. M. van Hest, Angew. Chem. Int. Ed. 2011, 123, 7208; e) M. C. van Oers, F. P. Rutjes, J. C. M. van Hest, J. Am. Chem. Soc. 2013, 135, 16308; f) R. Salva, J. F. Le Meins, O. Sandre, A. Brulet, M. Schmutz, P. Guenoun, S. Lecommandoux, ACS nano 2013, 7, 9298; g) P. van Rhee, R. Rikken, L. Abdelmohsen, J. C. Maan, R. J. M. Nolte, J. C. M. van Hest, P. Christianen, D. A. Wilson, Nat. comm. 2014, 5, 5010.

[23] a) D. A. Wilson, R. J. Nolte, J. C. M. van Hest, J. Am. Chem. Soc. 2012, 134, 9894; b) J. Howse, Nat. chem. 2012, 4, 247; c) L. K. E. A. Abdelmohsen, M. Nijemeiland, G. M. Pawar, G-J. A. Janssen, R. J. M. Nolte, J. C. M. van Hest, D. A. Wilson, ACS Nano 2016, 10, 2652.

[24] a) A. Adawy, E. Rebuffet, S. Törnroth-Horsefield, W. J. de Grip, W. J. van Enckevort, E. Vlieg, Cryst. Growth Des. 2013, 13, 775; b) A. McPherson, B. Cudney, Acta Crystallogr F 2014, 70, 1445; c) A. Adawy, W. Corbeek, E. de Ronde, W. J. van Enckevort, W. J. de Grip, E. Vlieg, CrystEngComm 2015, 17, 2602; d) K. M. Boyko, V. O. Popov, M. V. Kovalchuk, Russ. Chem. Rev. 2015, 84, 853; e) F. Otálora, J. A. Gavira, J. D. Ng, J. M. García-Ruiz, Prog. Biophys. Mol. Biology 2009, 101, 26.

[25] a) E. F. Garman, M. Weik, Synchrotron Radiat. News 2015, 28, 15; b) E. F. Garman, 
Science 2014, 343, 1102.

[26] a) D. M. Vriezema, J. Hoogboom, K. Velonia, K. Takazawa, P. C. M. Christianen, J. C. Maan, A. E. Rowan, R. J. M. Nolte, Angew. Chem. Int. Ed. 2003, 42, 772; b) S. M. Kuiper, M. Nallani, D. M. Vriezema, J. J. Cornelissen, J. C. van Hest, R. J. M. Nolte, A. E. Rowan, Org. Biomol. Chem. 2008, 6, 4315.

[27]D. A. Wilson, R. J. M. Nolte, J. C. M. van Hest, Nat. Chem. 2012, 4, 268.

[28] a) A. Adawy, E. G. G. van der Heijden, J. Hekelaar, W. J. P. van Enckevort, W. J. de Grip, E. Vlieg, Cryst. Growth Des. 2015, 15, 1150; b) A. Adawy, W. J. van Enckevort, E. S. Pierson, W. J. de Grip, E. Vlieg, CrystEngComm 2014, 16 , 9800.

[29] a) D. Erdemir, A. Y. Lee, A. S. Myerson, Acc. Chem. Res. 2009, 42, 621; b) P. G. Vekilov, Nanoscale 2010, 2, 2346; c) M. Sleutel, A. E. S. van Driessche, Proc. Nat. Acad. Sci. U.S.A. 2014, 111, E546; d) A. M. Streets, S. R. Quake, Phys. Rev. Letters 2010, 104, 178102; e) J. M. García-Ruiz, J.Struct. Biology 2003, 142 22; f) P. G. Vekilov, Prog. Cryst. Growth Charact. Mater.; g) T. Yamazaki, Y. Kimura, P. G. Vekilov, E. Furukawa, M. Shirai, H. Matsumoto, A. E. S. van Driessche, K. Tsukamoto, Proc. Nat. Acad. Sci. U.S.A. 2017, 114, 2154.

[30] a) Y. Li, V. Lubchenko, M. A. Vorontsova, L. Filobelo, P. G. Vekilov, The J. Phys. Chem. B 2012, 116, 10657; b) M. A. Vorontsova, H. Y. Chan, V. Lubchenko, P. G. Vekilov, Biophys. journal 2015, 109, 1959; c) D. Maes, M. A. Vorontsova, M. A. Potenza, T. Sanvito, M. Sleutel, M. Giglio, P. G. Vekilov, Acta Crystallogr F 2015, 71, 815.

[31]a) U. Weierstall, Philosophical Transactions of the Royal Society B: Biological Sciences 2014, 3690, 20130337; b) H. N. Chapman, P. Fromme, A. Barty, T. A. White, R. A. Kirian, A. Aquila, M. S. Hunter, J. Schulz, D. P. De Ponte, U. Weierstall, R. B. Doak, F. R. N. C. Maia, A. V. Martin, I. Schlichting, L. Lomb, N. Coppola, R. L. Shoeman, S. W. Epp, R. Hartmann, D. Rolles, A. Rudenko, L. Foucar, N. Kimmel, G. Weidenspointner, P. Holl, M. Liang, M. Barthelmess, C. Caleman, S. Boutet, M. J. Bogan, J. Krzywinski, C. Bostedt, S. Bajt, L. Gumprecht, B. Rudek, B. Erk, C. Schmidt, A. Homke, C. Reich, D. Pietschner, L. Struder, G. Hauser, H. Gorke, J. Ullrich, S. Herrmann, G. Schaller, F. Schopper, H. Soltau, K-U. Kuhnel, M. Messerschmidt, J. D. Bozek, S. P. Hau-Riege, M. Frank, C. Y. Hampton, R. G. Sierra, D. Starodub, G. J. Williams, J. Hajdu, N. Timneanu, M. M. Seibert, J. Andreasson, A. Rocker, O. Jonsson, M. Svenda, S. Stern, K. Nass, R. Andritschke, C-D. Schroter, F. Krasniqi, M. Bott, K. E. Schmidt, X. Wang, I. Grotjohann, J. M. Holton, T. R. M. Barends,; R. Neutze, S. Marchesini, R. Fromme, S. Schorb, D. Rupp, M. Adolph, T. Gorkhover, I. Andersson, H. Hirsemann, G. Potdevin, H. Graafsma, B. Nilsson, J. C. H. Spence, Nature 2011, 470, 73.

[32] K. T. Kim, J. J. Cornelissen, R. J. M. Nolte, J. C. M. van Hest, Adv. Mater. 2009, 21, 2787. 


\section{WILEY-VCH}

TOC text

Polymeric stomatocytes are utilized as a promising template to effectuate confined crystallization. These glassy stomatocytes facilitate the characterization of the encapsulated compounds using different electron microscopy methodologies without causing any background diffraction. More importantly, they provide their (crystalline) cargos with adequate shield from the electron beam's radiation damage .

Keyword: Confined Crystallization

Alaa Adawy, * Zakariae Amghouz, Jan C. M. van Hest and Daniela A. Wilson

Title ((Submicron polymeric stomatocytes as promising templates for confined crystallization and diffraction experiments))

ToC figure ((Please choose one size: $55 \mathrm{~mm}$ broad $\times 50 \mathrm{~mm}$ high or $110 \mathrm{~mm}$ broad $\times 20 \mathrm{~mm}$ high. Please do not use any other dimensions))

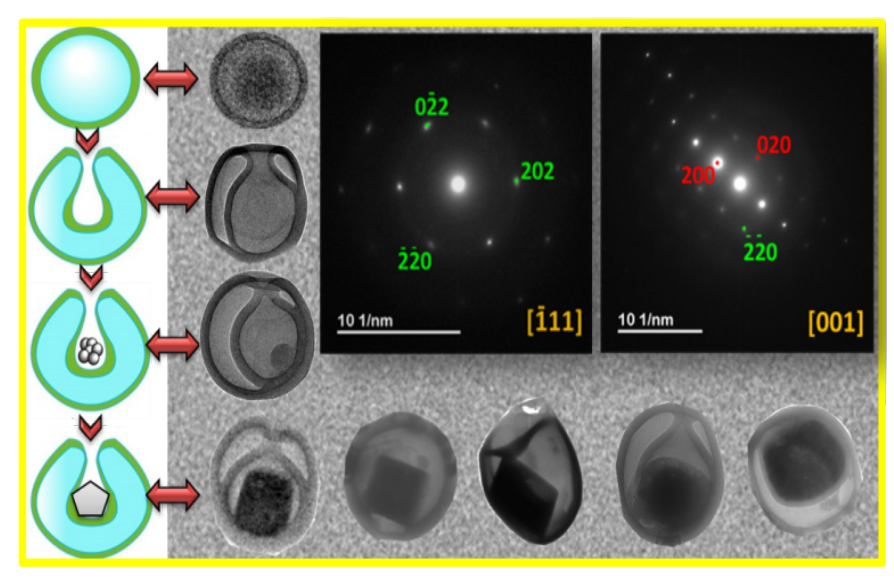




\section{WILEY-VCH}

((Supporting Information can be included here using this template))

Copyright WILEY-VCH Verlag GmbH \& Co. KGaA, 69469 Weinheim, Germany, 2016.

\section{Supporting Information}

Title ((Submicron polymeric stomatocytes as promising templates for confined crystallization and diffraction experiments))

Alaa Adawy, * Zakariae Amghouz, Jan C. M. van Hest and Daniela A. Wilson *

Note S1: An explanation for the formation of nanoscopic up to macroscopic scale, hexagonally-packed hollow hoops (HHHs), beads on a string and tubules when simulatenous assembly and encapsulation of inorganic compounds was attempted:-

The ease of KDP crystal growth in this system may be attributed to the low concentration needed for this compound to generate supersaturation.' However for the other inorganic compunds with relatively high solubility values, different structures were obtained. This can be explained as follow. Beside the encountered increase in the aqueous phase surface tension that changed the interaction between the PS core and its surroundings, the crystallization conditions caused two other related effects. First, it caused the salting out of the PEG segments that in turn encountered an increase in their intramolecular association among their chains. This eventually led to the contraction of PEG coils. Since $\mathrm{SO}_{4}^{-2}$ has a much stronger salting out effect than that of $\mathrm{Cl}^{-}$and $\mathrm{ClO}_{3}{ }^{-}$(Hofmeister series), the precipitation of PEG-PS in $\left(\mathrm{NH}_{4}\right)_{2} \mathrm{SO}_{4}$ is understandable. Secondly, incubating these structures at low temperature increased the effective PS : PEG chain length. This, besides the salting out effect, decreased the flexibility of the membranes by decreasing the stretching degree of their PS chains, which favored the formation of cylindrical over spherical bilayered structures. For several block copolymers, it was shown that the effective increase in the hydrophobic to hydrophilic ratio stimulates the morphological transitions from spherical vesicles to large compound vesicles and HHHs. ${ }^{5,}$,

\section{Supporting figures}




\section{WILEY-VCH}
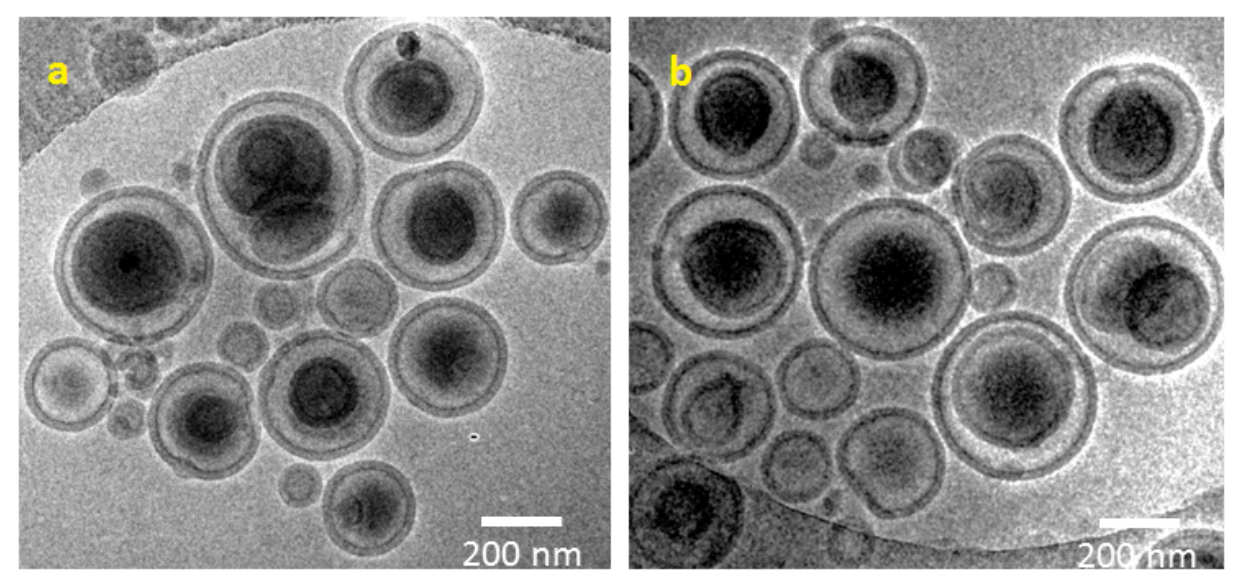

Figure S1. Cryo-TEM micrographs (a, b) of stomatocytes, assembled as explained in section $d$ of the experimental procedure) in the presence of $\mathrm{NaClO}_{3}$ solution. Only stomatocytes with diameter $\geq 200 \mathrm{~nm}$ have a very dark cargo, which is an indication of crystal growth. 


\section{WILEY-VCH}
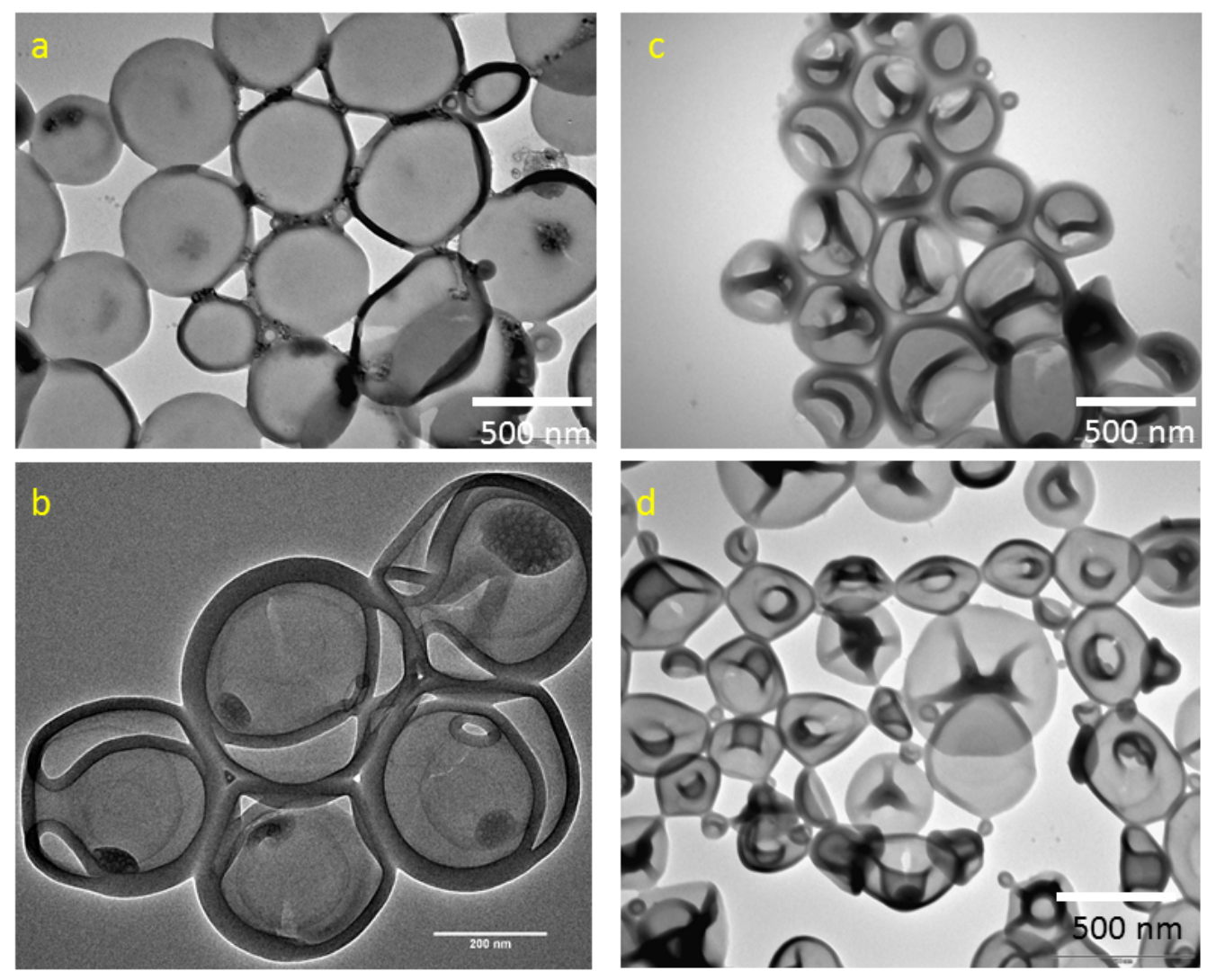

Figure S2. Dry-TEM micrographs of polymersomes prepared by using different organic solvent proportions. Polymersomes (a) that directly transformed into large planar discs when they were self-assembled in a solution containing 4:1 dioxane:THF organic mixture, resulted in stomatocytes (b) with inner compartments of almost the same size $(\varnothing \approx 300 \mathrm{~nm})$ after reverse dialysis. On the other hand, polymersomes prepared by using the conventional 4:1 THF:dioxane ratio at otherwise identical conditions are smaller (c) and after reverse dialysis lead to the formation of stomatocytes with inner compartments of $\varnothing \approx 110 \mathrm{~nm}(\mathrm{~d})$.

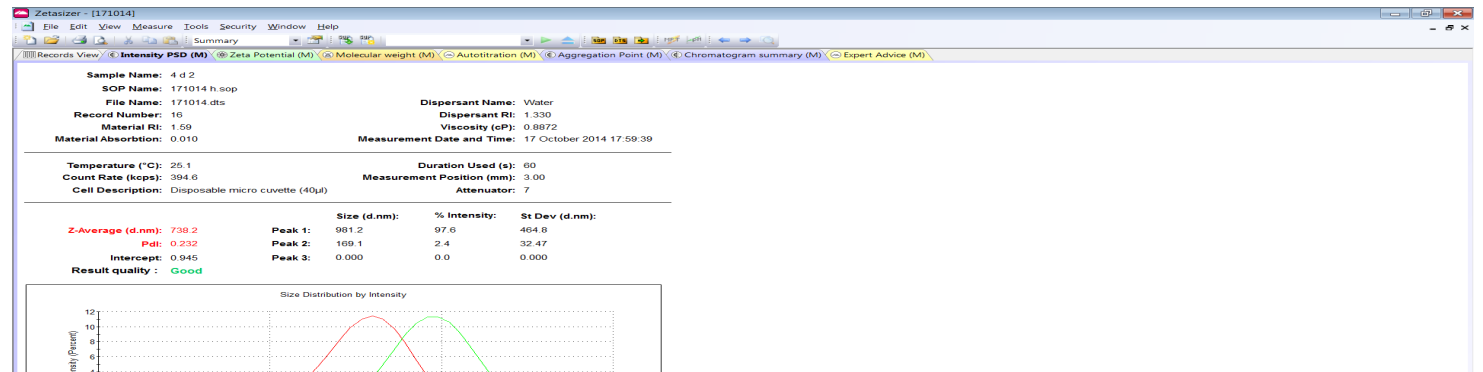


Figure S3. Size distribution data as measured by using DLS for polymersomes prepared by using different THF:dioxane organic solvent ratios. The green curve corresponds to polymersomes prepared in THF:dioxane ratio of 1:4 $\left(\mathrm{d}_{\mathrm{H}}=728 \mathrm{~nm}, \mathrm{PdI}=0.232\right)$ and the red curve corresponds to those prepared in THF:dioxane ratio of $4: 1\left(\mathrm{~d}_{\mathrm{H}}=324 \mathrm{~nm}, \mathrm{PdI}=0.198\right)$.

\section{WILEY-VCH}
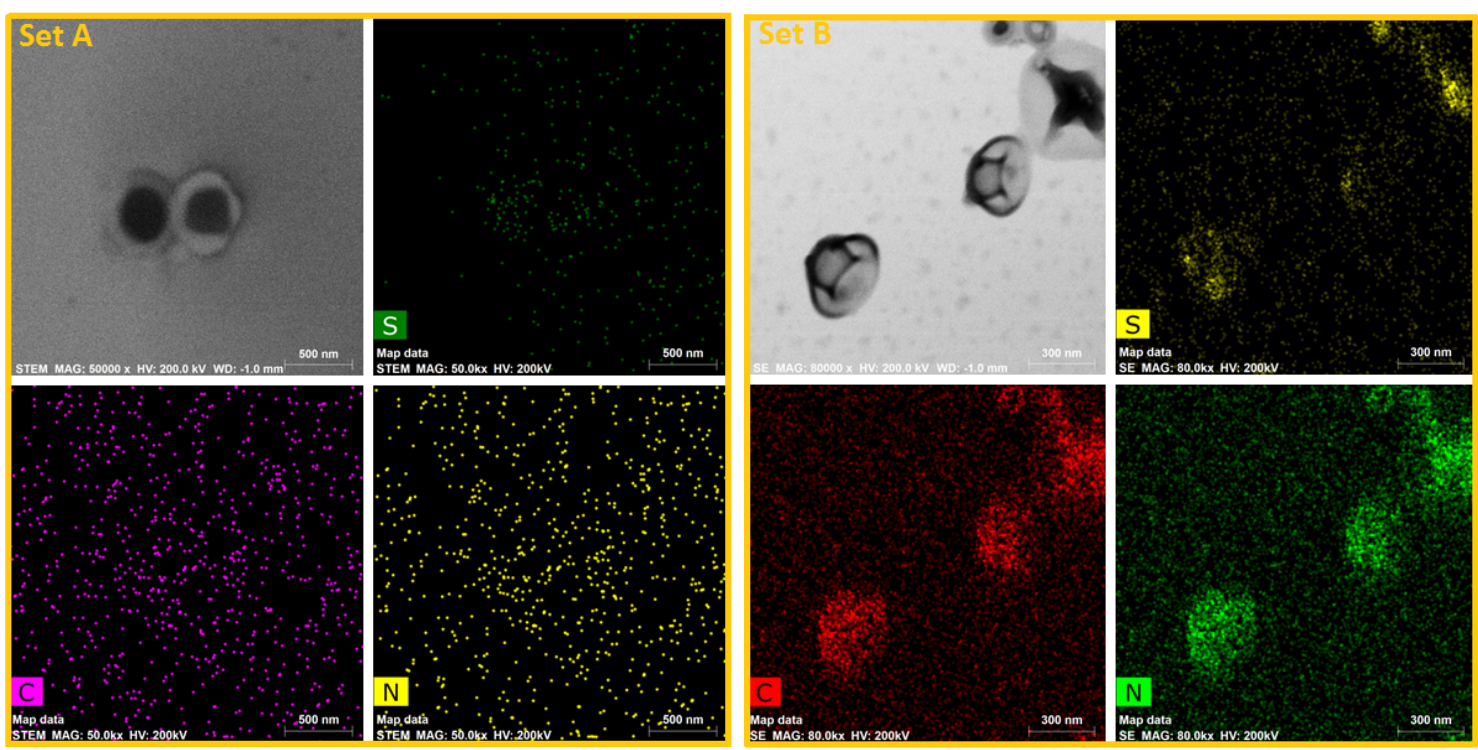

Figure S4. Dry Bright Field-STEM micrographs with the corresponding EDX mapping for sulfur (S), carbon (C) and Nitrogen (N) of stomatocytes containing HEWL possessing tight (set A) and wide (set B) openings. Only stomatocytes with small opening (set A) could entrap the protein as indicated by the sulfur content in EDX mapping.

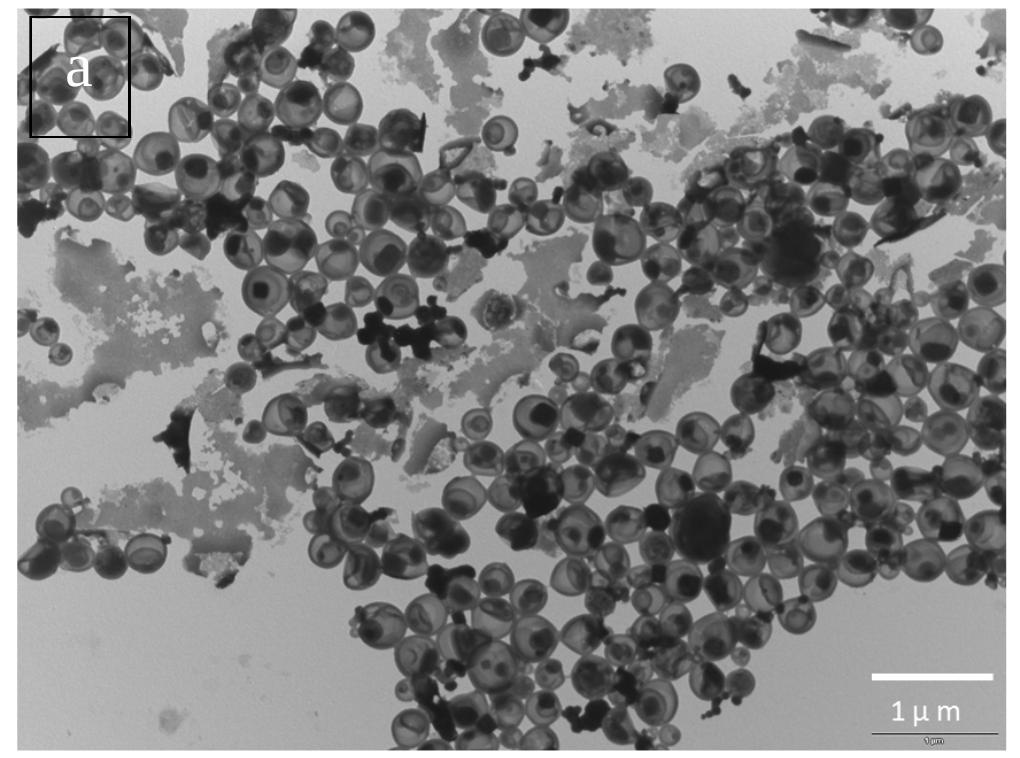




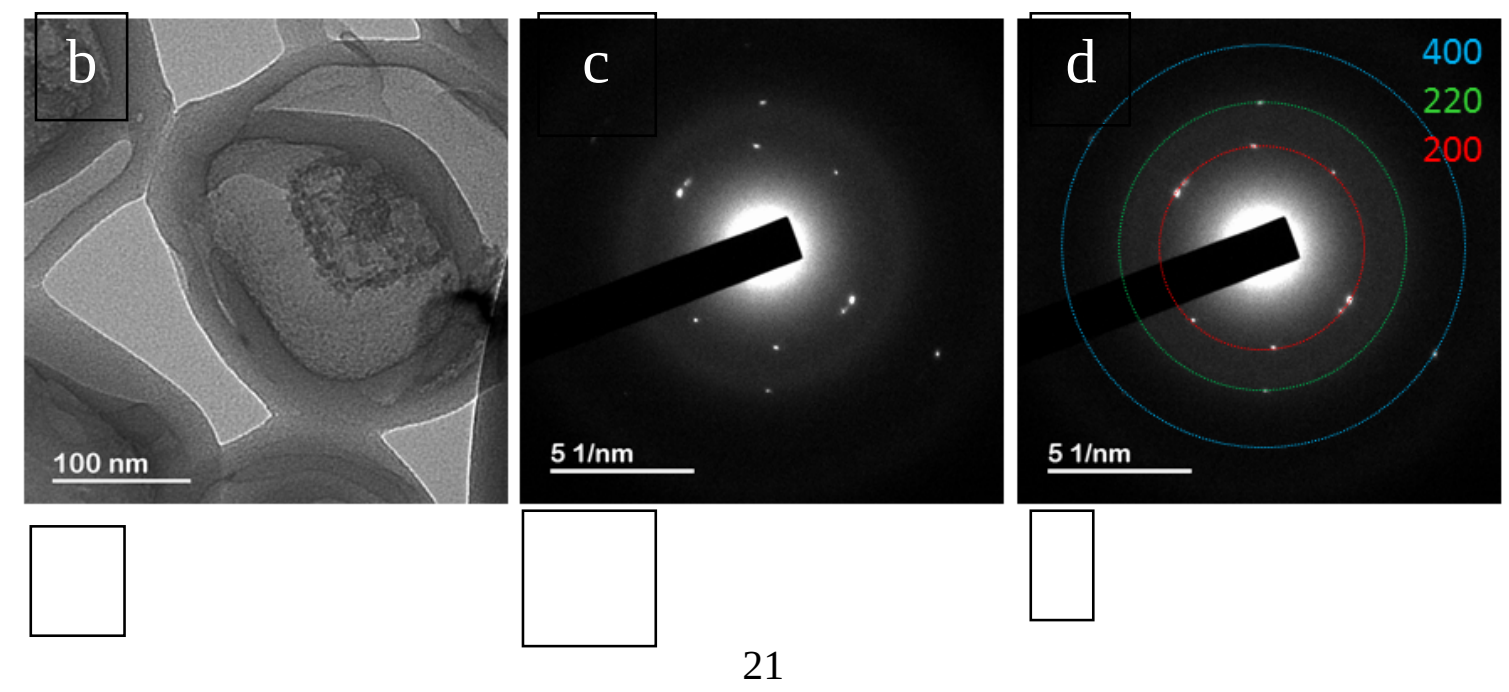

\section{WILEY-VCH}
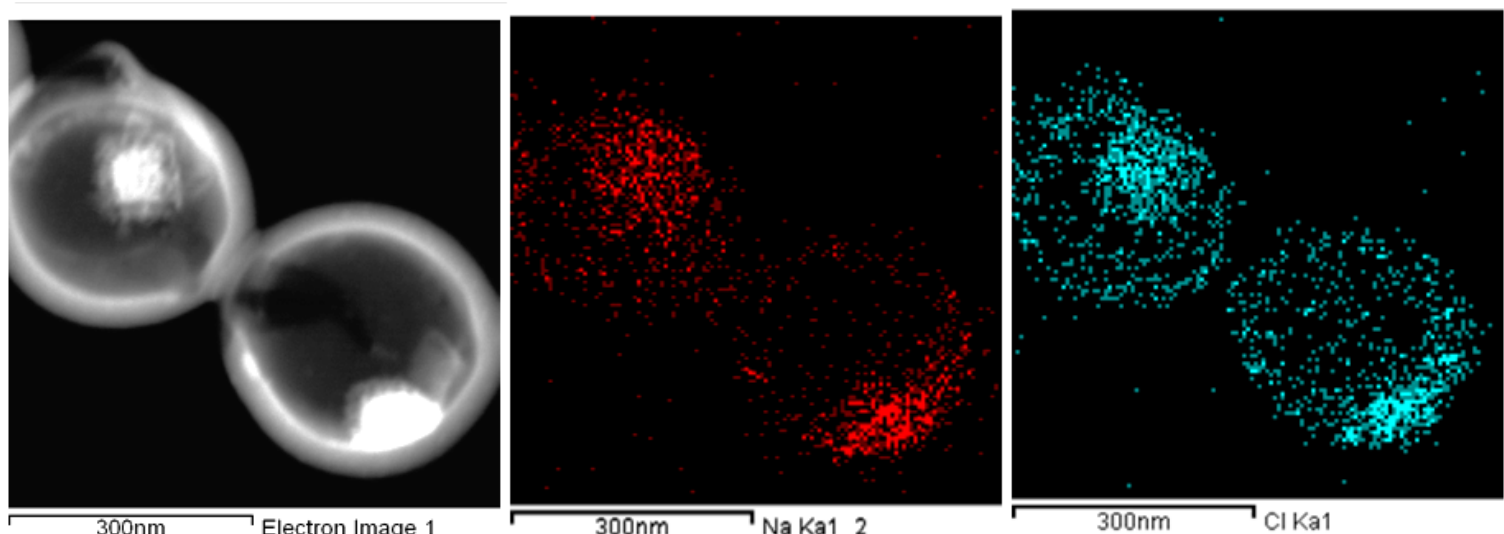

Figure S5. (a) dry-TEM micrograph of an overview of stomatocytes encapsulating $\mathrm{NaCl}$ crystals; (b) dry-TEM micrograph of an encapsulated NaCl Crystal; (c) SAED pattern for encapsulated $\mathrm{NaCl}$ crystal and (d) its associated indexing which shows the observed hkl reflections for cubic space group Fm-3m ( $a=5.6402 \AA$; ICSD PDF4: 05-0628); (e) DFSTEM micrograph of two stomatocytes containing $\mathrm{NaCl}$ crystals, together with (f, g) EDX elemental maps for $\mathrm{Na}$ (red) and $\mathrm{Cl}$ (cyan).

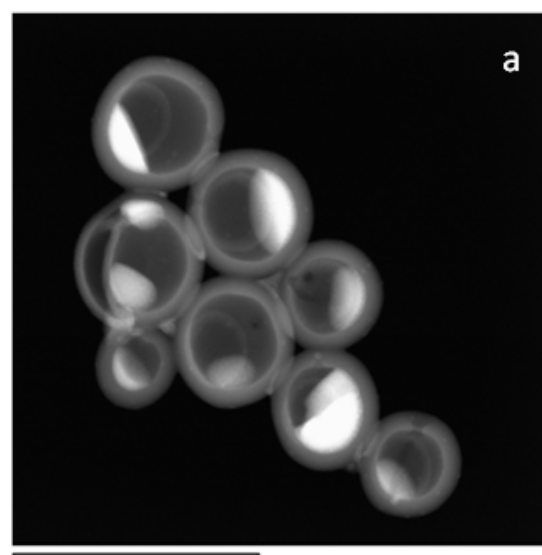

$700 \mathrm{~nm}$

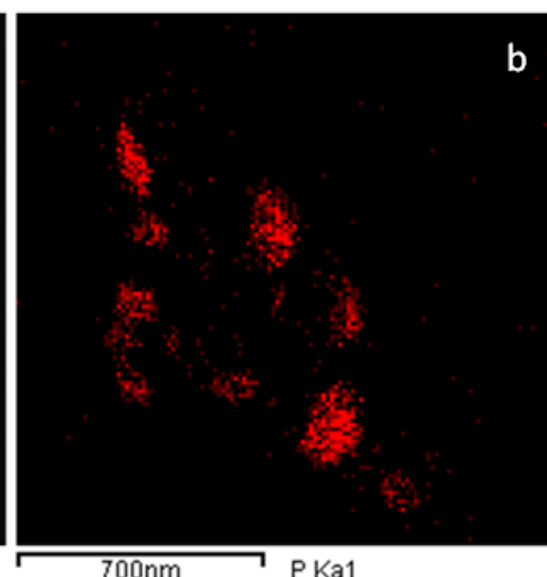

$700 \mathrm{~nm}$

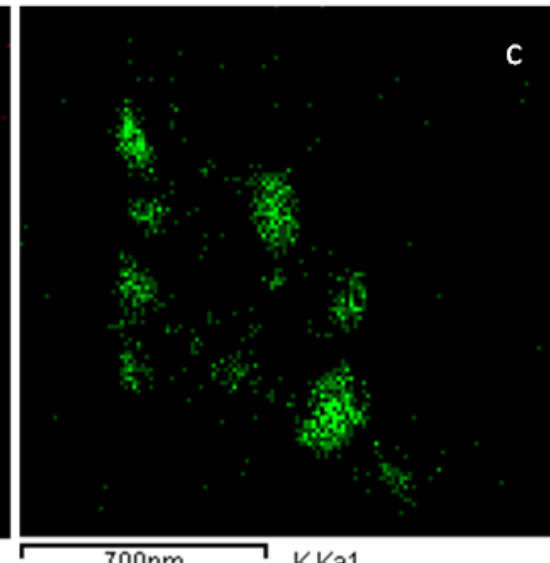

$700 \mathrm{~nm}$

$\mathrm{KKa}$ 


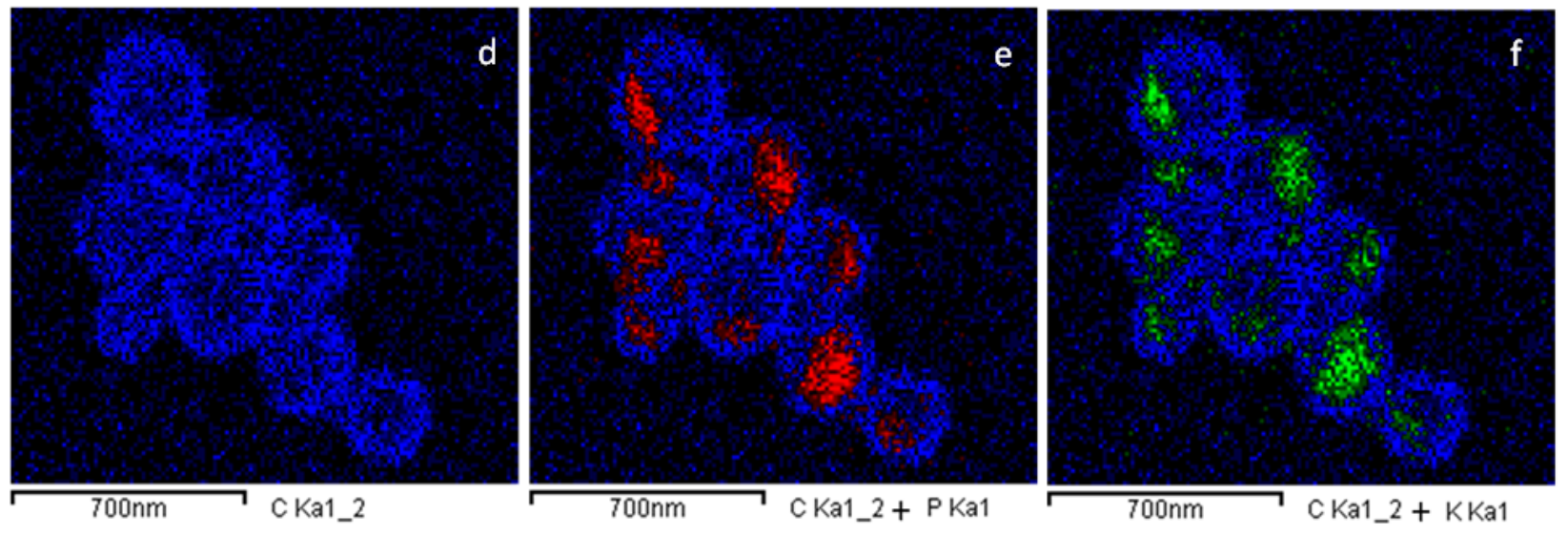

Figure S6. DF-STEM micrographs for a) stomatocytes containing the melting KDP crystals, together with EDX elemental maps for b) Phosphorus (red, P), c) Potassium, (green, K), d)

Carbon (blue, C), e) $\mathrm{C}+\mathrm{P}$ and f) $\mathrm{C}+\mathrm{K}$. 
WILEY-VCH

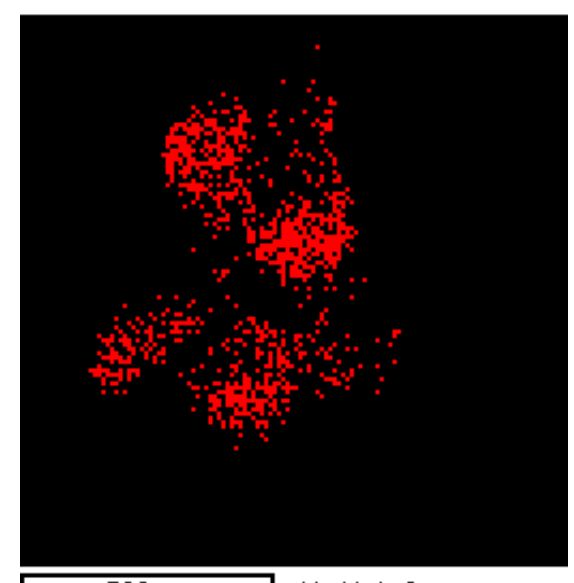

$700 \mathrm{~nm}$ NaKa1_2 
Figure S7. DF-STEM micrograph with corresponding EDX mapping of sodium carbon (purple), sodium (red) and chlorine (green) for stomatocytes containing melting $\mathrm{NaClO}_{3}$ crystals.

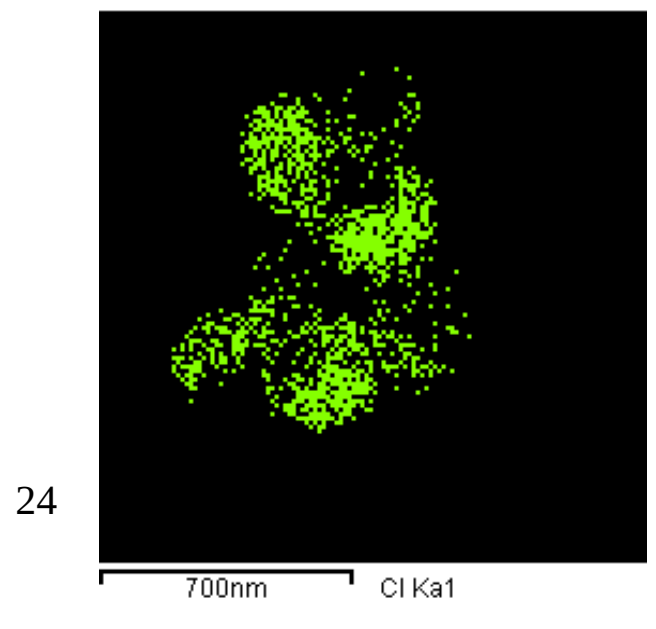

\section{WILEY-VCH}
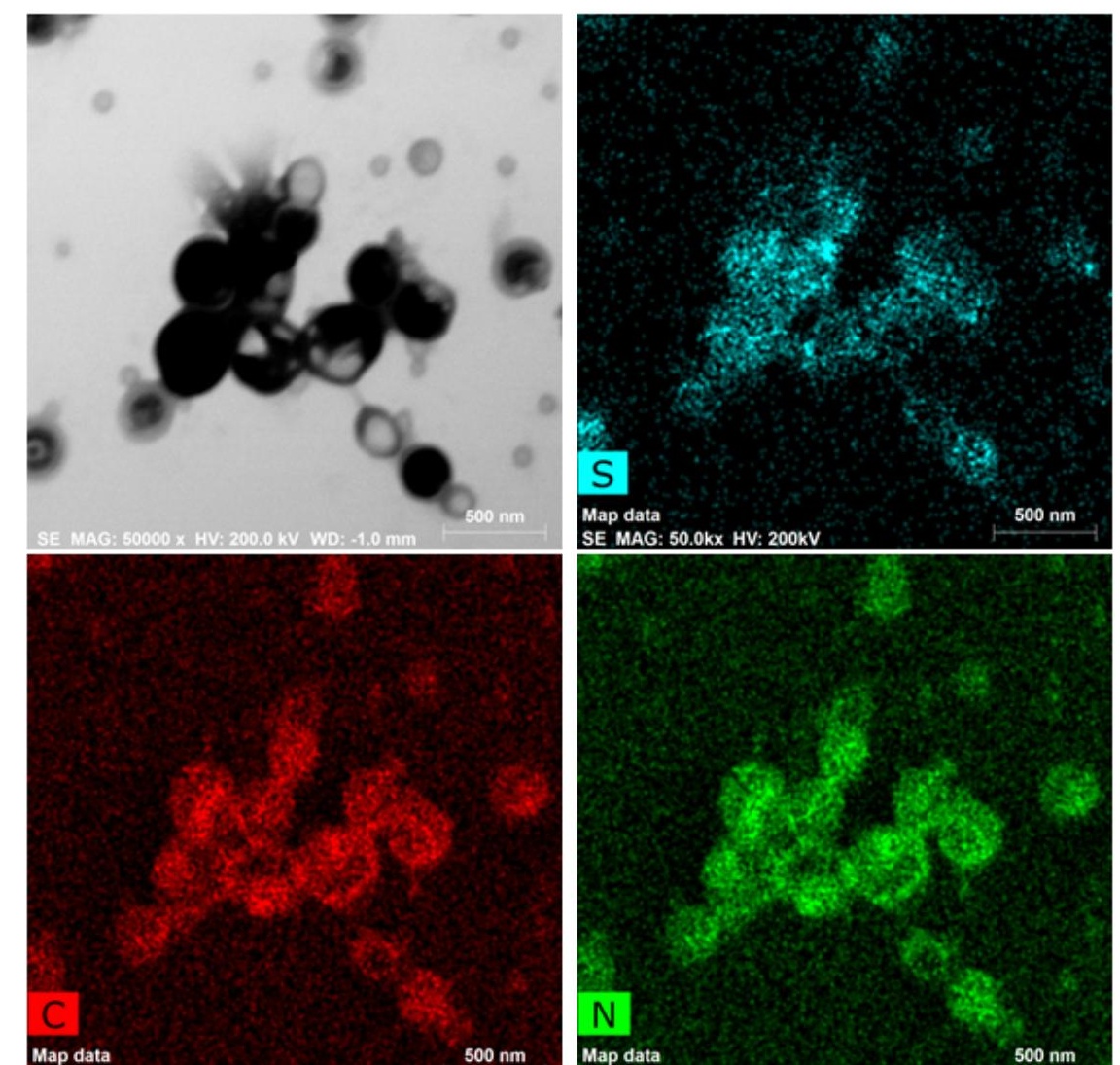
Figure S8. BF-STEM micrograph with corresponding EDX mapping of Sulfur (cyan), Carbon (red) and Nitrogen (green) in polymersomes containing HEWL.

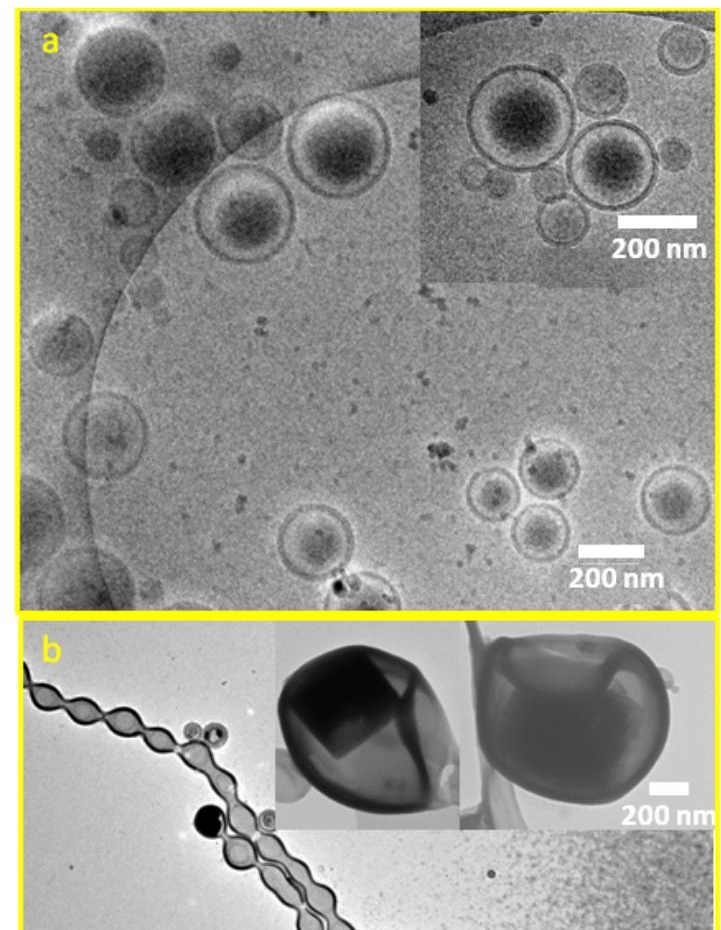




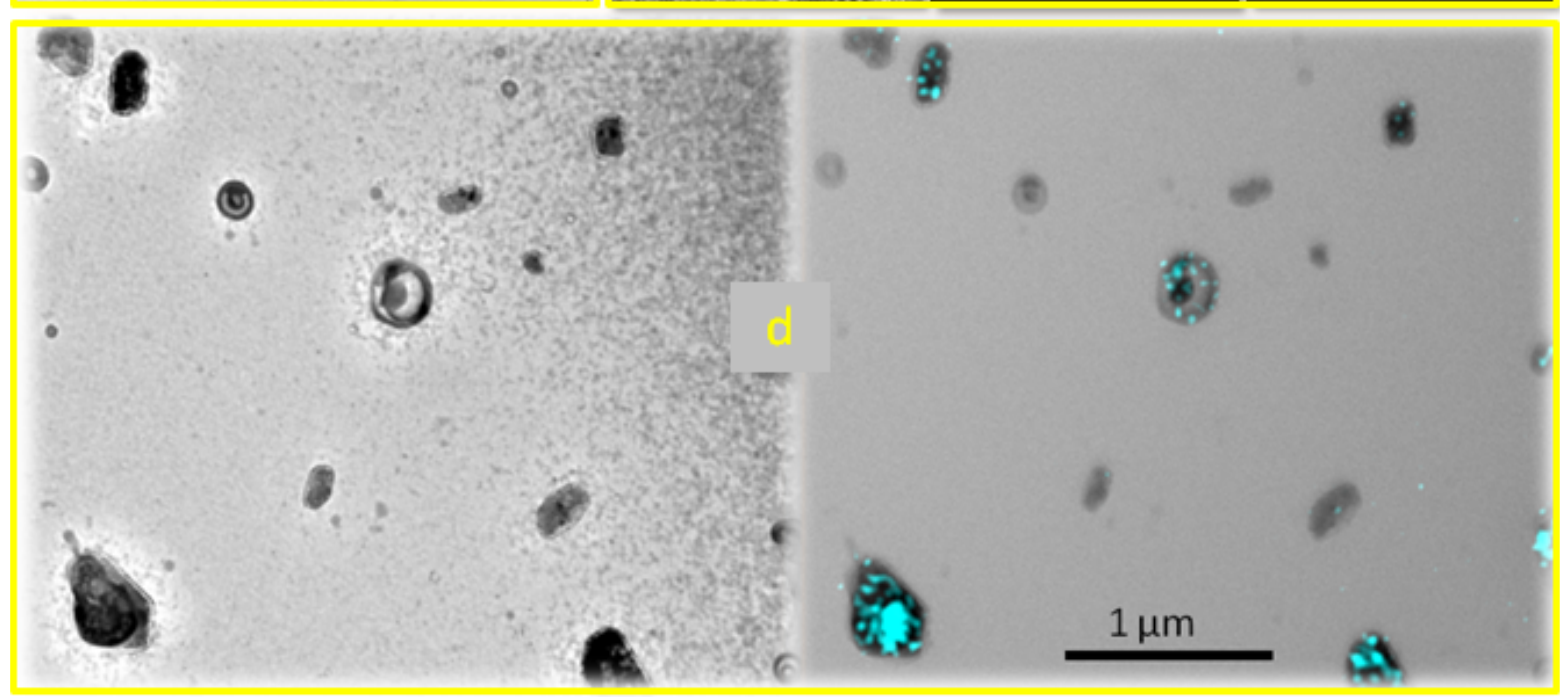

Figure S12 (a) When the stomatocytes were set to encapsulate a crystallization solution of HEWL, structures resembling crystals surrounded by thin transparent films were monitored using dry-TEM. However, the surrounding film was evaporated within two seconds of exposure (from $\mathrm{a}_{\text {top }}$ to $\mathrm{a}_{\text {bottom }}$ ), while these crystals did not. (b) SAED pattern obtained in cryoconditions for a HEWL crystal resulted in periodic diffraction spots, which in a couple of seconds vanished, indicating the vulnerable nature of the protein crystals and the electron beam radiation damage. (c) SAED for a cryo-cooled stomatocyte that appeared to be encapsulating HEWL resulted in diffraction spots which revealed an amorphous content of the precipitant $(\mathrm{NaCl})$ solution. These spots did not vanish, which indicates that they were not originating from a HEWL crystal. (d) EDX map of sulfur (displayed in cyan and overlapped with BFSTEM micrograph) showed the coexistence of free submicron-sized crystals and stomatocytes with these suspicious crystals. Dense sulfur was not detected from the stomatocytes. This indicates that the crystals inside the stomatocytes were originating from the precipitant and not HEWL. 